Florida International University FIU Digital Commons

\title{
An investigation of the effects of a school-based intervention on feelings of personal expressiveness in multi-problem adolescent youth
}

Richard E. Albrecht

Florida International University

DOI: $10.25148 /$ etd.FI13101566

Follow this and additional works at: https://digitalcommons.fiu.edu/etd

Part of the Psychology Commons

\section{Recommended Citation}

Albrecht, Richard E., "An investigation of the effects of a school-based intervention on feelings of personal expressiveness in multiproblem adolescent youth" (2005). FIU Electronic Theses and Dissertations. 1146.

https://digitalcommons.fiu.edu/etd/1146 
Miami, Florida

AN INVESTIGATION OF THE EFFECTS OF A SCHOOL-BASED

INTERVENTION ON FEELINGS OF PERSONAL EXPRESSIVENESS

IN MULTI-PROBLEM ADOLESCENT YOUTH

A thesis submitted in partial fulfillment of the

requirements for the degree of

MASTER OF SCIENCE

in

PSYCHOLOGY

by

Richard E. Albrecht

2005 
To: Dean R. Bruce Dunlap

College of Arts and Sciences

This thesis, written by Richard E. Albrecht, and entitled An Investigation of the Effects of a School-Based Intervention on Feelings of Personal Expressiveness in Multi-Problem Adolescent Youth, having been approved in respect to style and intellectual content, is referred to you for judgment.

We have read this thesis and recommend that it be approved.

Wendy Silverman

Jonathan Tubman

William M. Kurtines, Major Professor

Date of Defense: March 30, 2005

The thesis of Richard E. Albrecht is approved.

Dean R. B/uce Dunlap 7 College of Arts and Sciendé

- Dean Dbuglas Wartzok University Graduate School

Florida International University, 2005 


\section{DEDICATION}

I dedicate this thesis to my mother who remains steadfast in supporting me and my father who, even after all these years without him, continues to show me that in one way or another, d...u...m...m pretty much says it all. 


\section{ACKNOWLEDGMENTS}

I owe many thanks to many people who have helped me throughout this process over the past years. I would like to thank Dr. Kurtines for his time, guidance, and reassurance that completing such a project was within my reach. To Dr. Silverman and Dr. Tubman, I also extend heartfelt thanks for your help on this project, and your guidance throughout my time in this program. I would also like to thank my mother and father who have helped me take a leap and pursue the kind of work I love. And to Arlen and Angel, I thank you for being there in the quiet times when I needed someone to help me through, even when what I said gave you a headache. 


\begin{abstract}
OF THE THESIS
AN INVESTIGATION OF THE EFFECTS OF A SCHOOL-BASED

INTERVENTION ON FEELINGS OF PERSONAL EXPRESSIVENESS
\end{abstract}

IN MULTI-PROBLEM ADOLESCENT YOUTH

by

Richard E. Albrecht

Florida International University, 2005

Miami, Florida

Professor William M. Kurtines, Major Professor

This study was conducted to determine the effects of the Changing Lives Program intervention on troubled adolescents' feelings of personal expressiveness, believed to be one domain of positive identity development. Forty-three intervention and twenty nonintervention comparison control participants were given a battery of pre-, post-, and follow-up assessments including the Personally Expressive Questionnaire (Waterman, 1995), which was used to derive participants' feelings of personal expressiveness scores. Using Repeated Measures Analysis of Multivariate Analysis (RMANOVA), a significant four-way interaction of Time X Condition X Gender X Ethnicity was found relative to the Control, Roy's $\Theta=.166, \mathrm{~F}(2,47)=3.899, p<.027$ indicating that intervention participants' feelings of personal expressiveness did increase significantly relative to the control group. Furthermore, the results suggest differential outcomes based on ethnicity, suggesting the need for future study with respect to specificity of effects and mechanisms of identity formation in differing ethnic subgroups. 


\section{TABLE OF CONTENTS}

CHAPTER

PAGE

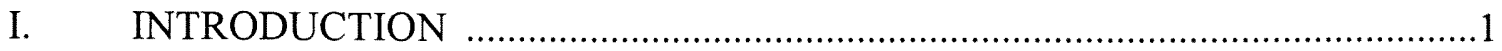

Evaluating the Impact of Positive Youth Development Programs ........................ 3

Understanding Mechanisms of Change .............................................................

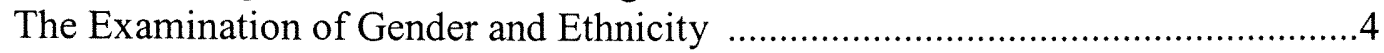

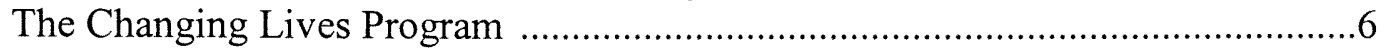

Measuring Processes Underlying Change .......................................................

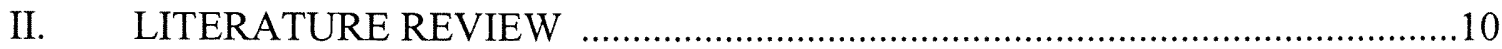

Personal Expressiveness and Self-Development ...........................................10

Implications for Interventions Targeting Positive Identity Development ............11

Interventions With Emerging Adults .............................................................12

Research Questions and Hypotheses .................................................................13

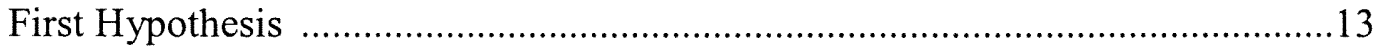

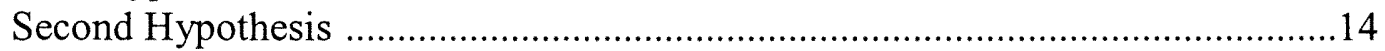

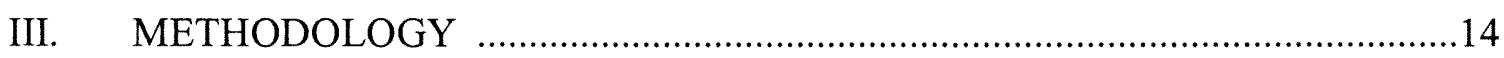

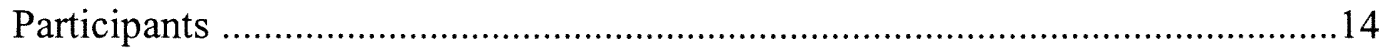

Participant Recruitment and Participation ……...............................................15

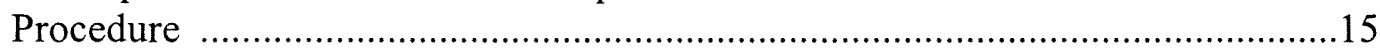

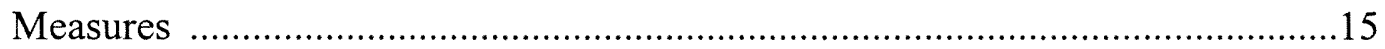

Personally Expressive Activities Questionnaire (PEAQ) ..................................15

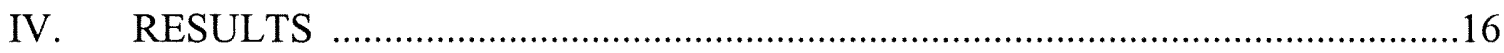

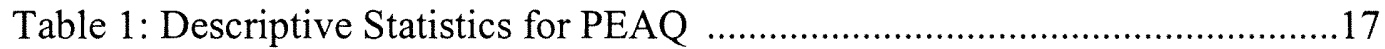

Table 2: Multivariate Tests of Significance ………............................................19

Figure 1: Condition by Gender Effects Pre to Post ...........................................20

Figure 2: Condition by Ethnicity Effects Pre to Post .........................................21

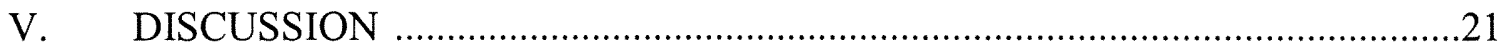

The CLP Intervention Approach and Personal Expressiveness ……...................25

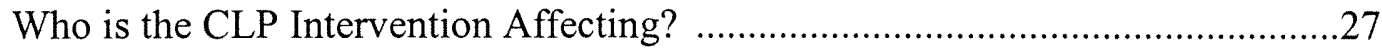

Working in Contexts of Heterogeneity and Diversity .........................................30

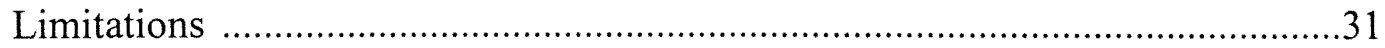

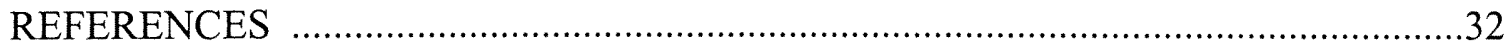




\section{INTRODUCTION}

There is mounting awareness of the importance, and growing interest in creating positive development programs designed to encourage and empower young people, particularly troubled youth (Brandtstadter \& Lerner, 1999; Catalano, Berglund, Ryan, Lonczak, \& Hawkins, 1999; Peterson \& Reid, 2003; Pittman, 2000). At the same time, there has been increasing recognition of the need for development of universitycommunity collaborative models of intervention (Lerner, Fisher, \& Weinberg, 2000) particularly geared toward promoting positive development (Damon, 2004; Damon \& Gregory, 2003). Such models involve a learning collaboration between scholars and community members that can serve as an essential part of the knowledge generation process (Eccles, 1996; Erickson \& Weinberg, 1998, 1999; Fisher, 1997; HigginsD'Alessandro, Fisher, \& Hamilton, 1998; Keys, Bemak, Carpenter, \& King-Sears, 1998). The recognition of this need, however, is recent and the development of alternative models has lagged behind that of other types of research models. Jensen, Hoagwood, and Trickett (1999), for example, describe two distinct models of research relevant to nationally funded types of research (e.g., by the National Institutes of Health).

The first and most prominent model described was "Efficacy Research" (Jensen et al. 1999), a model that focuses on generating knowledge of the efficacy of intervention strategies primarily developed by funded research evaluated in well-controlled studies conducted at university clinic and laboratory settings. Such studies have resulted in efficacious preventive interventions for several high-risk behaviors and/or outcomes (c.f. Ferrer-Wreder, Stattin, Lorente, Tubman, \& Adamson, 2004). As Spoth, Greenberg, Bierman, and Redmond (2004) have pointed out, however, too frequently efficacious 
interventions implemented in schools and communities through grant funding fail to survive the withdrawal of that funding (Adelman \& Taylor, 2003). A chief reason for the limited sustainability of interventions begun by research projects may be that successful research implementation of the project does not require building local ownership and infrastructure capacity required for the institutionalization of interventions (e.g., adequate personnel with appropriate leadership capabilities and other requisite skills, as well as reliable sources of funding (see Lerner, 1995).

A second and far less prominent model was referred to as "Outreach Research," a model that has been rarely and poorly funded relative to the efficacy research model. Outreach research is conducted in "real-world" community settings. At one level, Outreach Research can be understood in terms of the issues of efficacy versus effectiveness. Efficacy Research is a model that focuses on generating knowledge of the efficacy of intervention strategies evaluated in well-controlled studies conducted at university clinic and laboratory settings designed to maximize internal validity using quantifiable outcomes, well-established measures, manualized interventions, experimental or quasi- experimental designs, etc. In this literature, "efficacy" is usually contrasted with "effectiveness," where effectiveness has to do with how well knowledge generated in university clinic or lab setting generalizes to (and can be applied in) "realworld" settings. In contrast to theory-driven clinic or lab-based Efficacy Research, Outreach Research is rooted in local and particular needs in "real-world" community settings and uses a bottom-up approach to developing interventions. Because it emerges out of (and remains rooted in) the community, "effectiveness" is built into interventions developed under this model (Kurtines, 2005). 
Outreach research thus has an intrinsic concern with "effectiveness" (external validity) as well as efficacy (internal validity) where criteria for effectiveness includes intervention strategies that are palatable, feasible, durable, affordable, and sustainable in real-world settings. The focus of outreach research is thus on generating knowledge of effective as well as efficacious intervention strategies. Jensen et al. (1999) noted that, with respect to the question of how many prevention and youth development programs meet these criteria, the current answer is "Very few (if any), indeed."

\section{Evaluating the Impact of Positive Youth Development Programs}

Recent reviews of positive youth development programs reveal an accumulation of evidence that (a) these programs can have an impact on young people and (b) that this field has made considerable strides, including increased methodological rigor and sophistication. (c.f. Catalano, Berglund, Ryan, Lonczak, \& Hawkins 1999; FerrerWreder, et al., 2004). Despite the consistent pattern of overall positive findings in the literature, important gaps in research-based knowledge remain, particularly with respect to the impact of youth development interventions. The Catalano et al. (1999) review, for instance, reported only relatively short-term (pre, post, and follow-up) studies with outcomes evaluated using criteria derived from the efficacy research model, namely, studies evaluating the magnitude of short-term quantitative change in continuous variables using experimental (RCTs) or quasi-experimental designs. Indeed, the studies were selected for inclusion in the review largely because they fit the definition of "wellevaluated" within the efficacy research model. More important, because their focus was on efficacy or outcome analyses, none of study designs included specific analyses of mediators or moderators of intervention response. 


\section{Understanding Mechanisms of Change}

As interest in research on positive development programs has grown, there has also been a growing literature (Hinshaw, 2002; Kazdin, 2001; Holmbeck \& Shapera, 1999; Holmbeck, 1997) regarding the need for understanding mechanisms of change, including the need to understand the complex role both endogenous and exogenous moderators play in intervention response. According to Holmbeck \& Shapera (1999), a moderator is a variable that specifies the condition under which an initial or manipulated variable has an effect on an outcome. Within moderation analyses, the aim is to evaluate the way a relationship between two variables varies as a function of the moderator variable. In this way, the effect specific variables have on intervention outcome can be examined. As the Catalano et al. (1999) review illustrates, however, the literature contains little such mechanism-oriented intervention research. This knowledge gap is particularly important for how community based programs are implemented and evaluated.

\section{The Examination of Gender and Ethnicity}

Because the diversity of problems and populations within school based youth development interventions more closely approximate the type of heterogeneous populations found in effectiveness research rather than those found in efficacy research, community based interventions need to pay particular attention to moderators of intervention response. This is especially true in the case of identity development because of the explicitly co-constructive nature of the formation of a personal sense of identity (Erikson, 1968) and the important role that "ethnic" identity (as one component of identity) plays in the outcome of this process. Moreover, the role of ethnicity as a 
potential cultural/contextual moderator of identity development is a process that is likely of particular importance to minority youth in multicultural contexts.

As discussed by Spencer and Markstrom-Adams (1990), for example, little is known about the effects of exogenous contextual variables on developing children's and adolescents' identities though there has been growing evidence showing that ethnicity has a strong effect on the developmental contexts in which individuals operate (Schwartz \& Montgomery, 2002; Betancourt \& Lopez, 2002; Szcapocznik \& Kurtines, 1993). This evidence has highlighted the need for further research, particularly with respect to the development and implementation of interventions geared toward diverse populations. More specifically, there has been a call for research to better understand the moderating effects of ethnicity on intervention outcomes utilizing samples drawn from ethnically heterogeneous social contexts (Spencer \& Markstrom, 1990).

The few previous studies that have been done regarding the effects of ethnicity on identity development specifically utilized samples drawn from ethnically homogenous minority samples living in ethnically homogenous minority contexts (Ollech \& McCarthy, 1997; Schultheiss \& Blustein, 1994), or the multi-ethnic samples used were drawn from highly functioning emerging adults (Schwartz \& Montgomery, 2002). Though these studies do show that ethnicity moderates intervention outcomes, no studies have been done utilizing a sample drawn from multi-problem adolescents found within contexts of ethnic heterogeneity. Furthermore, because gender roles tend to vary between different cultures (Schwartz \& Montgomery, 2002; Sorrel \& Montgomery, 2001; Cole, 
1998), it is reasonable to believe that intervention outcomes may thus also be moderated by gender.

Studies using ethnically homogenous White majority samples have shown gender differences in both process and outcome in the impact of identity interventions on identity development (Schwartz \& Montgomery, 2002). Coupled with the previously mentioned studies on the moderating effects of ethnicity, these findings suggest that gender and ethnicity do moderate intervention outcomes in interventions which target identity development. Furthermore, these studies take the first steps toward addressing what may be unique mechanisms of identity formation for differing ethnic subgroups, although before such mechanisms can be understood regarding adolescent identity development, the potential moderating effects of gender and ethnicity must be examined using a sample drawn from contexts of ethnic heterogeneity.

\section{The Changing Lives Program}

Drawing its sample from the richly diverse and pluralistic greater Miami area, previous research of the Changing Lives Program (CLP) intervention has responded to the growing recognition of cultural/contextual variables as potential moderators of intervention response. Kurtines and Montgomery (2005), for example, highlighted the importance of considering various exogenous factors (gender, ethnicity, SES,...) that may act to "moderate" the effects of the intervention. Specifically, two previous studies, the Life Course Intervention study (LCI; Lewis-Arango, 2003) and the Possible Selves Qualitative Extension Relational Data Analysis (PSQ-QE RDA; Kortsch, 2003) study specifically examined the effects of the CLP intervention while attempting to better understand the potential moderating effects of gender and ethnicity on intervention 
outcomes. The results of these studies provided support for the importance of gender and ethnicity as moderators of intervention effects, and that these effects varied across outcome measures. Though not definitive, the differential patterns of overall positive change in intervention participants with regard to gender and ethnicity in each study suggests that further examination of the potential moderation role of the exogenous variables gender and ethnicity is still needed.

Utilizing the opportunity a heterogeneous population offers toward understanding the mechanisms of positive intervention change, the Youth Development Project (YDP) at Florida International University undertook as part of a program of community-based efficacy/effectiveness outcome research, an evaluation of the Changing Lives Program (CLP) as part the Miami Youth Development Project. The Changing Lives Program, which is now in its second decade of existence, began as a grass roots response to an urgent and growing need in the community - that of young people desperately trying to find their sense of self while also needing to reconnect with their families and take command of their lives - and has subsequently, evolved into a broad-based community partnership. This partnership consists of Florida International University (FIU) (http://www.fiu.edu/choice.html), the public research university in Miami; Communities in Schools (CIS) (http://www.cisnet.org/), a private, non-profit organization that is part of a community-based national network for delivering community resources to schools; and Miami-Dade County Public Schools (MDCPS) (http://www.dadeschools.net/), the fourth largest school system in the United States with its program of community based alternative public high schools located throughout greater Miami. The CLP counseling services provided by the Miami Youth Development Project are currently available to all 
of the MDCPS alternative high schools on an ongoing basis, serving approximately 200 to 250 students each year. This multiethnic youth population comes to the alternative schools with a history of attendance, behavior, or motivational problems in their neighborhood school, with many coming from inner city, low-income families that exist within a community context of disempowerment, limited access to resources, and pervasive violence, crime, and substance abuse.

For its developmental framework, the Changing Lives Program draws from both psychosocial developmental theory (Erikson, 1968) and life course theory (Elder, 1998), referred to as a "psychosocial developmental life course" approach. From psychosocial developmental theory, the CLP adopts a view of adolescence as a developmental stage at which an individual begins to choose "who I am," and is first confronted with the difficult challenge (and responsibility) of choosing the goals, roles, and beliefs about the world that give their life direction and purpose as well as, coherence and integration (i.e., a positive sense of identity). From life course theory, the CLP seeks to foster a sense of empowerment for intervention participants and adopts an emphasis on how individuals construct their own life course through the choices and actions they make within the constraints and opportunities of history and social circumstances.

As noted by Swenson (2004), the alternative high schools in which the CLP is implemented draw their students from a wide array of community settings characterized by an extraordinary diversity that is typical of urban communities the world over. In this context, the identification and isolation of the effects of a single, relatively brief intervention has proven challenging among the rich complexity of theoretically meaningful exogenous variables that influence participants' lives. Specifically, Swenson 
(2004) noted that the CLP was developed for a population that: presents with a heterogeneity of problems; spans a critical developmental period involving significant biological, cognitive, affective, and social change at the intraindividual level (preadolescence to adulthood); and encompasses a richly diverse range of socio-demographic characteristics, including multiple long-term (and powerful) socialization experiences (e.g., gender, ethnic, cultural, racial, and SES).

Although the CLP has undergone preliminary research with marginalized youth using quantitative and qualitative short-term quasi-experimental designs (Ferrer-Wreder et al, 2002; Kurtines, Kortsch, Lewis Arango, 2001; Kurtines, Montgomery, Lewis Arango, \& Kortsch, in press), little previous research within this framework has systematically examined the effects of these potential moderators (Swenson, 2004). Consequently, this study was intended, in part, to contribute to the understanding of meaningful exogenous variables (e.g., gender, ethnic, cultural, racial, and SES) that are believed to exert powerful influence on every level of participants' lives.

\section{Measuring Processes Underlying Developmental Change}

As part of the previous research with the CLP intervention (Kurtines, 2005), recent work (Swenson, 2003; 2004) has begun to draw on the growing literature on the moderation of intervention effects (Kazdin, 2001; Hinshaw, 2002; Holmbeck, 1997). Consistent with this direction of research, the specific aim of this study is to take a first step toward examining the potential moderation effects of contextual exogenous variables on positive develop outcome of the CLP using feelings of personal expressiveness as one measure within the domain of positive development. That is, this study seeks to examine the moderation effects of gender and ethnicity on intervention participants' feelings of 
personal expressiveness as measured by the Personally Expressive Questionnaire (PEAQ; Waterman, 1995).

\section{LITERATURE REVIEW}

\section{Personal Expressiveness and Self-Development}

Research suggests that individuals engaged in personally expressive behaviors show more positive life outcomes than those who engage in activities considered less personally expressive (Csikszentmihalyi, 1990b; 1988, 1975; Waterman et al., 2003; 1993). Feelings of personal expressiveness are defined as the deep satisfaction that accompanies engagement in activities or goals that utilize one's unique or innate potentials and that represent one's basic purpose in living (Waterman, 1993; Schwartz, Kurtines, \& Montgomery, 2004). These feelings result from incorporating activities, goals, and ideals into one's sense of identity and reflect one's core sense of being (Waterman, Schwartz, Goldbacher, Green, Miller, Philip, 2003). Specifically, while engaging in personally expressive activities, individuals experience 1) unusually intense involvement, 2) a special fit or meshing with the activities, 3) feelings of being intensely alive, 4) feelings of completeness or fulfillment, 5) an impression that this is what one was meant to do, and 6) feelings of who one really is (Waterman et al., 2003). Thus, the developmental implications of Waterman' claim, if true, are considerable. That is, it follows from this that a dispositional integration of activities or goals that are personally expressive into one's on-going life course has the potential to make a substantial positive contribution to one's basic sense of purpose in living (Waterman, 1993; Schwartz et al., 2004). 
Surprisingly, despite the important implication of engaging in personally expressive activities for the development of a positive sense of self or a positive identity, the concept of feelings of personal expressiveness has had little or no impact on, nor focus in the literature on promoting positive development with multi-problem youth.

\section{Personal Expressiveness and Self Development:}

\section{Implications for Interventions Targeting Positive Identity Development}

The experience of feelings of personal expressiveness may thus be plausibly hypothesized to be positively related to self-development in identity development particularly during adolescence, as adolescence is considered a time when one begins to address "who one is" (Erikson, 1959; 1968). More specifically, positive identity development may be linked to the ability of individuals to explore and express "who they really are." It may, consequently, be possible to develop intervention strategies specifically targeting feelings of personal expressiveness with the aim of fostering the process of the development of a positive identity in intervention participants, particularly adolescents and emerging adults. Such intervention strategies would focus on enhancing feelings of personal expressiveness (and fostering the engagement in personally expressive activities), hoping to build on participants' strengths and interests, and trying to take advantage of participants' skills and confidence as a means of promoting positive development (Nakamura \& Csikszentmihalyi, 2002; Parr, Montgomery, \& Bell, 1998). Such interventions would attempt to help participants better understand their own feelings of personal expressiveness and sense of self by orienting participants toward incorporating activities into their lives that they feel are personally expressive, drawing on Waterman et al.'s (2003) six descriptors of feelings of personal expressiveness (listed 
above). A recent study by Schwartz, Kurtines, and Montgomery (2005) has shown that such intervention is feasible in a sample of college-aged emerging adults.

\section{Intervention with Emerging Adults}

Specifically, Schwartz, Kurtines, \& Montgomery (2005) demonstrated that an intervention utilizing two different identity development strategies, one cognitive and one emotion-focused, showed that intervention participants feelings of personal expressiveness varied significantly based on the strategy used. The cognitive approach attempted to help participants generate and weigh options in their lives meant to achieve their life goals, while the emotion-focused strategy focused on participants gaining better understanding or discovering their own feelings of what they wanted, as well as the innate abilities and strengths they already possess which may aid in achieving their goals. Specifically, individuals using the cognitive strategy showed no change in their feelings of personal expressiveness, while those in the emotion-focused strategy showed significant change in their feelings of personal expressiveness scores. Qualitative responses regarding their experiences in the intervention further suggest that such an intervention was not only received positively, but that an intervention focused on developing one's already-present abilities is perceived by intervention participants to be highly valuable in helping them achieve their future goals.

Most important to the current study, however, was the intervention outcome which was shown to vary by participants' ethnicity, with Hispanic individuals differing significantly from their White/Non-Hispanic counterparts. The outcome of this study suggests that feelings of personal expressiveness are amenable to change through intervention. However, the differential effect for ethnic subgroups, as well as the use of a 
relatively high-functioning sample of college students-- while providing tentative evidence that such an intervention may be effective in helping participants act as better agents in their own lives-- do not provide guidance regarding such intervention with troubled adolescents.

Consistent with the Schwartz, Kurtines, \& Montgomery (2005) findings, this study seeks to investigate whether feelings of personal expressiveness are amenable to change in a sample of multi-ethnic, multi-problem youth, in hopes of setting the stage for future intervention work targeting feelings of personal expressiveness with adolescents such as this.

\section{Research Questions and Hypotheses}

This study addressed two research questions: first, whether participating in the intervention condition (CLP) was associated with differential positive change over Time (Pre, Post) in intervention participants' feelings of personal expressiveness, as measured by the PEAQ relative to control condition (CC) participants, and; second, whether the exogenous contextual variables Gender and Ethnicity were moderators of intervention response. The associated null and alternative hypotheses were as follows:

\section{First Hypothesis:}

Null Hypothesis: There will be no significant 2-way Time (Pre, Post) by Condition (CLP, $\mathrm{CC}$ ) interaction for intervention response as measured by the PEAQ.

Alternative Hypothesis: There will be a significant 2-way Time (Pre to Post) by Condition (CLP, CC) interaction for intervention response as measured by the PEAQ, with the CLP intervention participants showing a significantly greater positive increase 
in feelings of personal expressiveness than participants in the non-intervention control condition (CC).

Second Hypothesis:

Null Hypothesis: There will be no significant 3-way interactions between Time, Condition, and Gender and Time, Condition, and Ethnicity and no significant 4-way interactions between or Time, Condition, Gender, and Ethnicity for intervention response as measured by the PEAQ

Alternative Hypothesis: There will be a significant 3- and/or 4-way interactions between Time, Condition, and Gender, Time, Condition, and Ethnicity, or Time, Condition, Gender, and Ethnicity for intervention response as measured by the PEAQ and, in the context of the absence of previous empirical research to provide guidelines, with an unspecified differential response pattern.

\section{METHODOLOGY}

\section{$\underline{\text { Participants }}$}

This analysis was done using archival data from the Youth Development Project (YDP) comprised of 92 multi-problem youth who attended Miami-Dade County alternative, public high schools between the years 2000 and 2002. Of these, 43 completed the PEAQ as part of their fall pre-test, winter mid-year, and end-of-year follow-up evaluations, as well as attended one hour counseling group sessions with 6-7 other members, each week for the Fall and Winter semesters. The intervention group was comprised of 31 males and 39 females with 41\% Hispanic, 29\% African-American, 21\% Caucasian, and 9\% Bi-ethnic or "Other." The comparison control group was comprised 
of 11 males and 9 females with 40\% Hispanic, 25\% Caucasian, 20\% African-American, and $15 \%$ Bi-ethnic or "Other."

\section{Participant Recruitment and Participation}

Participants either chose or were referred by the school guidance counselor to participate with the CLP intervention. The CLP meetings were once a week with a group of up to ten adolescent participants and a CLP intervention team. The CLP intervention team consisted of a graduate psychology student as the facilitator, a co-facilitator, and one or more undergraduate psychology students as assistants. All facilitators met weekly with the Youth Development Project Clinical Coordinator to discuss any clinical issues and for ongoing supervision.

\section{Procedure}

The intervention participants for this study took part in the CLP facilitated counseling for an hour, once a week at their high schools. The CLP counseling, as part of the public high schools' ongoing efforts, was implemented through the guidance office. Conducting the counseling sessions were seven CLP facilitators that were each accompanied by an intervention team comprised of a co-facilitator and one or two assistants for group sessions. Pretest assessments were administered the week preceding the beginning of group counseling in the Fall of 2000, with Winter mid-year assessments occurring during February, and end-of-year follow-up assessments occurring in May.

\section{Measures}

Personally Expressive Activities Questionnaire (PEAQ)

The PEAQ (Waterman, 1995) assesses change in the personal and prosocial content of participants' life goals and change in the degree to which they experience the 
pursuit of these goals as personally satisfying and expressive of their unique potentials.

The PEAQ asks participants to identity three life goals that are important to them and rate the activities necessary to achieve those goals on fourteen 7-point Likert items. Six of the items rate the goals for feelings of personal expressiveness (PE), six for hedonic enjoyment (HE), and two for flow challenge (FC; Csikszentmihalyi, 1990); from these, mean scores for PE, HE, and FC are computed. Hedonic enjoyment refers to feelings of enjoyment that are not deemed to be personally expressive. Flow challenge refers to the individual's perception of fit between their skill levels and the contextual challenges they describe.

The PEAQ provides only two items per goal regarding the FLOW-C scale. Alphas for PE and HE have been reported as .77 and .90 , respectively. Because $\mathrm{HC}$ and FC were not directly targeted as domains of positive development, $\mathrm{HE}$ and $\mathrm{FC}$ will not be examined in this study.

\section{RESULTS}

This study addressed two research questions previously described, i.e., whether participating in the intervention condition (CLP) was associated with differential positive change over Time (Pre, Post) and whether the exogenous contextual variables Gender and Ethnicity were moderators on intervention response.

The study used a mixed (within and between) quasi-experimental comparison control design. The data analytic procedure selected was a mixed design Repeated Measures Multivariate Analysis of Variance (RMANOVA) to examine the associated null and alternative hypotheses described above. 
Specifically, $2 \times 2 \times 2 \times 4$ mixed design (within and between) RMANOVAs was used in which Time (Pre, post) was the within (repeated) factor and Condition (CLP, CC), Gender (Female, Male), and Ethnicity (Latino/Hispanic/White/Bi-Ethnic-Other) were the between group factors. The RMANOVA was thus utilized to evaluate participants' differential intervention response, as measured by the PEAQ, while evaluating for possible Gender and Ethnicity moderation of the effects of condition. The multivariate null hypothesis for these statistical tests for the null hypotheses was set at .05 .

The first RMANOVA was conducted using 43 participants in the Intervention Condition and 20 participants in the Control Condition, serving as a one semester nonintervention comparison using PE as the dependent variable. Tables $1 \mathrm{a}$ and $\mathrm{b}$ represent the descriptive statistics for the PEAQ, PE subscale.

Table 1: Descriptive Statistics for PEAQ, Personal Expressiveness Subscale

\begin{tabular}{|c|c|c|c|c|c|c|c|}
\hline \multirow[b]{2}{*}{ Ethnicity } & \multirow[b]{2}{*}{ Condition } & \multicolumn{2}{|c|}{ Mean } & \multicolumn{2}{|c|}{ Std. Deviation } & \multicolumn{2}{|c|}{$\mathrm{N}$} \\
\hline & & Time 1 & Time 2 & Time 1 & Time 2 & Time 1 & Time 2 \\
\hline \multirow{2}{*}{$\begin{array}{l}\text { White/Non- } \\
\text { Hispanic }\end{array}$} & Intervention & 5.9000 & 6.6667 & .99722 & .51370 & 5 & 5 \\
\hline & Control & 5.3333 & 3.3317 & 1.4142 & 2.831 & 2 & 2 \\
\hline \multirow{2}{*}{ Hispanic } & Intervention & 5.9815 & 6.0926 & 1.0323 & 1.077 & 9 & 9 \\
\hline & Control & 4.5833 & 6.5833 & .82496 & .58926 & 2 & 2 \\
\hline \multirow{2}{*}{$\begin{array}{l}\text { African- } \\
\text { American }\end{array}$} & Intervention & 6.1667 & 6.3542 & .81650 & .62639 & 8 & 8 \\
\hline & Control & 6.3333 & 5.4167 & .23570 & .35355 & 2 & 2 \\
\hline \multirow[t]{2}{*}{ Other } & Intervention & 5.6111 & 6.1667 & 1.7347 & 1.443 & 3 & 3 \\
\hline & Control & 5.3333 & 4.8878 & .16667 & .76884 & 3 & 3 \\
\hline \multirow{2}{*}{ Total } & Intervention & 5.9800 & 6.3000 & .99805 & .87533 & 25 & 25 \\
\hline & Control & 5.3889 & 5.0363 & .85797 & 1.606 & 9 & 9 \\
\hline
\end{tabular}


Table 1b: Descriptive Statistics for PEAQ PE subscale

Gender: Male

\begin{tabular}{llllllll}
\hline \hline & & \multicolumn{2}{c}{ Mean } & Std. Deviation & \multicolumn{2}{c}{ N } \\
\cline { 3 - 7 } Ethnicity & Condition & Time 1 & Time 2 & Time 1 & Time 2 & Time 1 & Time 2 \\
\hline $\begin{array}{l}\text { White/Non- } \\
\text { Hispanic }\end{array}$ & Intervention & 5.9444 & 6.2222 & 1.1824 & .63099 & 3 & 3 \\
& Control & 5.0833 & 5.0011 & 1.9383 & .16834 & 3 & 3 \\
\hline \multirow{2}{*}{ Hispanic } & Intervention & 5.1296 & 5.4263 & 1.6431 & 1.158 & 9 & 9 \\
& Control & 5.4667 & 4.7489 & 1.0739 & 1.570 & 6 & 6 \\
\hline \multirow{2}{*}{$\begin{array}{l}\text { African- } \\
\text { American }\end{array}$} & Intervention & 5.9722 & 5.5833 & .74100 & 1.168 & 6 & 6 \\
\hline \multirow{2}{*}{ Total } & Control & 4.5833 & 5.4167 & 2.7106 & 2.239 & 2 & 2 \\
\hline & Intervention & 5.5463 & 5.6113 & 1.3343 & 1.079 & 18 & 18 \\
\hline
\end{tabular}

Table 2 represents the multivariate tests of significance for the main effects for Time, Condition, and the Time by Condition interaction, and Time, Condition, Gender, and Ethnicity interaction effects on feeling of personal expressiveness. As can be seen by Table 2, there were no significant main effects for Time or Condition. There was also no significant two-way interaction effect, Time X Condition, which tested for the unmoderated effects of the intervention. In addition, neither the Time X Gender and Time X Ethnicity nor any three-way interactions of Time X Condition X Gender, nor Time X Condition X Ethnicity were significant. However, the four-way interaction of Time X Condition X Gender X Ethnicity, Roy's $\Theta=.165, \mathrm{~F}(2,47)=4.047, p<.024$ was significant, indicating that the intervention had a significant effect on feelings of personal expressiveness, and that this effect was moderated by both gender and ethnicity. 
Table 2: Multivariate Tests of Significance for the Repeated Factor Time and Time, Condition, Gender, and Ethnicity Interaction Effects

\begin{tabular}{|c|c|c|c|c|c|c|}
\hline Effect & & Value & $\overline{\mathrm{F}}$ & df & Error df & Sig. \\
\hline Time & $\begin{array}{l}\text { Roy's Largest } \\
\text { Root }\end{array}$ & .001 & $.026^{\mathrm{a}}$ & 1.000 & 49.000 & .871 \\
\hline Time*Gender & $\begin{array}{l}\text { Roy's Largest } \\
\text { Root }\end{array}$ & .000 & $.001^{\mathrm{a}}$ & 1.000 & 49.000 & .980 \\
\hline Time*Ethnicity & $\begin{array}{l}\text { Roy's Largest } \\
\text { Root }\end{array}$ & .035 & $.565^{\mathrm{a}}$ & 3.000 & 49.000 & .641 \\
\hline Time*Condition & $\begin{array}{l}\text { Roy's Largest } \\
\text { Root }\end{array}$ & .020 & $.967^{\mathrm{a}}$ & 1.000 & 49.000 & .330 \\
\hline $\begin{array}{l}\text { Time*Gender* } \\
\text { Ethnicity }\end{array}$ & $\begin{array}{l}\text { Roy's Largest } \\
\text { Root }\end{array}$ & .088 & $2.144^{\mathrm{a}}$ & 2.000 & 49.000 & .128 \\
\hline $\begin{array}{l}\text { Time*Condition* } \\
\text { Gender }\end{array}$ & $\begin{array}{l}\text { Roy's Largest } \\
\text { Root }\end{array}$ & .009 & $.428^{\mathrm{a}}$ & 1.000 & 49.000 & .516 \\
\hline $\begin{array}{l}\text { Time*Condition* } \\
\text { Ethnicity }\end{array}$ & $\begin{array}{l}\text { Roy's Largest } \\
\text { Root }\end{array}$ & .071 & $1.154^{\mathrm{a}}$ & 3.000 & 49.000 & .337 \\
\hline $\begin{array}{l}\text { Time*Condition* } \\
\text { Gender*Ethnicity }\end{array}$ & $\begin{array}{l}\text { Roy's Largest } \\
\text { Root }\end{array}$ & .165 & $4.047^{\mathrm{a}}$ & 2.000 & 49.000 & .024 \\
\hline
\end{tabular}

As can be seen in Figure 1, with respect to the moderating effects of Gender, both male and female intervention participants showed increases in their PE scores, with male intervention participants showing little positive change relative to their female counterparts. Males in the non-intervention control resemble intervention male participants, showing little to no improvement in their scores.

Females in the intervention condition showed a marked increase in PE scores from pre to post, while females in the non-intervention control group show a decrease in their PE scores. Study participants showed higher overall levels of feelings of personal expressiveness at pre-test relative to controls, with male and female participants 
starting with similar PE scores at pre-test. Post-test results for females, however, show a marked increase over their male intervention counterparts.

Figure 1: Condition by Gender Effects Pre to Post for PE
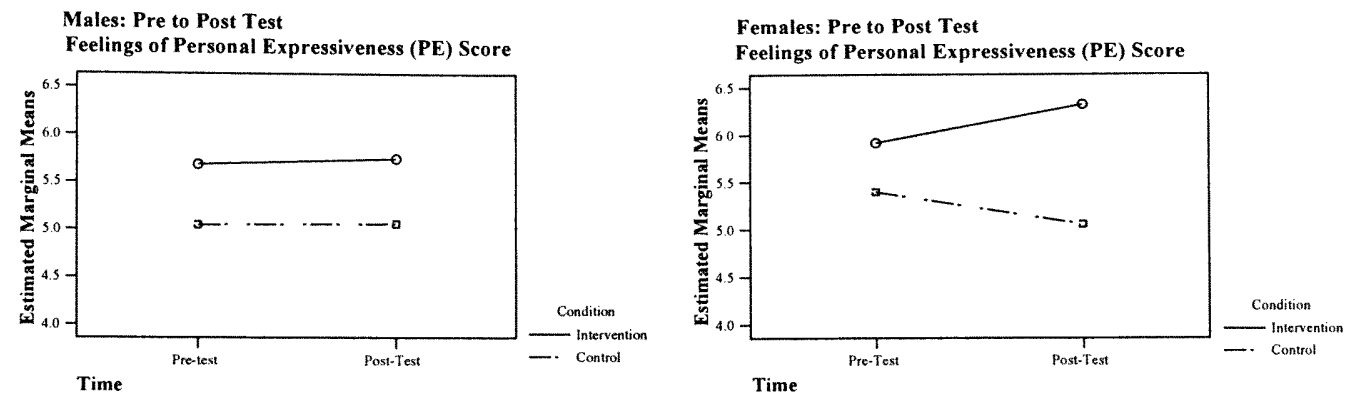

As can be seen in Figure 2, with respect to the moderating effects of Ethnicity on PE scores, Caucasian, Hispanic, Asian, and Bi-Ethnic/Other intervention participants showed increases in PE scores, but most notably, African-American intervention participants showed a slight decrease in their PE scores over time. All non-Intervention control participants (including Caucasian, African-American, and Bi-Ethnic/Other) showed decreases in their feelings of personal expressiveness except Hispanic youth in the non-intervention control group. For these control participants, PE scores increased even more so than Hispanic intervention participants. 

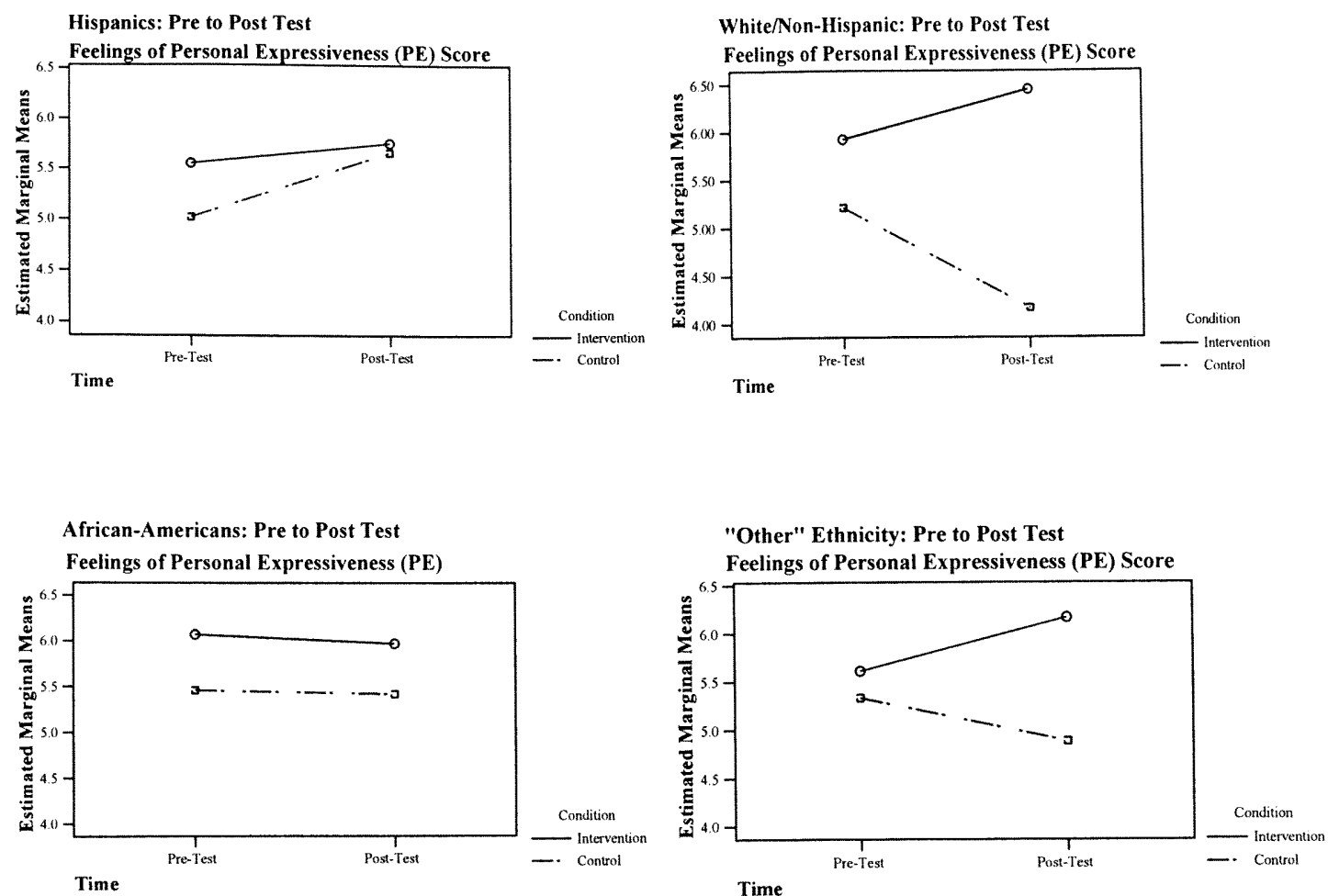

\section{DISCUSSION}

This thesis reports the results of a study conducted as part of a program of community-based efficacy/effectiveness outcome research evaluating the Miami Youth Development Project's intervention. A goal of this study was to extend the range and scope of the domains of positive development the Youth Development Project targets to include feelings of personal expressiveness. The findings of this study provide preliminary evidence that feelings of personal expressiveness are potential targets for future intervention with a multi-ethnic population. In addition, the findings of this study may also offer additional practical implications with respect to both the current literature 
and future directions in research with respect to developing intervention strategies for promoting personal expressiveness as a dimension of positive development.

As mentioned previously, a literature on developing interventions that target increasing personal expressiveness with the aim of fostering the process of the development of a positive identity has begun to evolve in the area of emerging adulthood. Schwartz, Kurtines, and Montgomery (2005), for example, reported the results of an exploratory study to investigate the impact of two types of intervention strategies (cognitive versus emotionally focused) on two types of identity development processes (self-construction and self-discovery). The self-constructive condition strategies focused on facilitating "self-construction" whereby individuals are encouraged to develop the orientations (style) and abilities (competence) needed to sort through externally presented options and to select the most favorable one. The emotionally focused strategy was characterized by the facilitation of "self-discovery," whereby individuals were encouraged to identify their "unique potentials" and to formulate goals and ideals that correspond to those potentials. The study was conducted on 90 emerging adult university students, and used a quasi-experimental design to evaluate the relative impact of the construction and discovery intervention strategies on exploration processes. A nonintervention comparison control condition was also included. For all three conditions, pretest assessments were conducted at the beginning of the semester and posttest assessments conducted at the end of the semester (approximately a 10-week interval). Posttest data were collected from control condition participants and from participants in the active conditions who completed the intervention. 
Consistent with their outcome expectations, Schwartz et al. (2005) reported that the overall pattern of quantitative outcome results provided support for the impact of cognitive strategies on self-construction exploration processes and of emotionally focused strategies on self-discovery exploration processes. The overall pattern of both the quantitative and qualitative results provided support for "specificity of effects." That is, the intervention strategies used in each condition did not have an equal impact on all of the identity exploration processes, either across domains (self-construction versus selfdiscovery) or within each domain. Changes in some, but not other, processes directly targeted by the intervention were observed in the emotionally-focused condition. This condition, with its self-discovery strategies, impacted feelings of personal expressiveness. Furthermore, the outcome varied by participants' ethnicity.

The Schwartz et al. (2005) study thus represents the emergence of a research literature on promoting feelings of personal expressiveness in moderately to highlyfunctioning adults in intervention efforts that target positive identity development which shows differential effects based on ethnicity. Little research, in contrast, has been done on younger populations or regarding troubled or "delinquent" youth (Csikszentmihalyi \& Rathunde, 1993; Csikszentmihalyi \& Larson, 1978) and their experience of feelings of personal expressiveness. While the Schwartz et al. (2005) study suggests that the transition into adulthood is challenging across socio-economic levels, there is a noticeable gap in the empirically supported intervention literature regarding feelings of personal expressiveness in the type of troubled adolescent youth targeted by the Changing Lives Program. As noted, this multiethnic youth population comes to the alternative schools with a history of attendance, behavior, or motivational problems in 
their neighborhood school, with many coming from inner city, low-income families that exist within a community context of disempowerment, limited access to resources, and pervasive violence, crime, and substance abuse. The gap in our understanding of effective intervention strategies for facilitating feelings of personal expressiveness thus takes on particular significance in the context of the development of interventions for this type of multi-problem adolescents for whom the transition toward adulthood is likely of particular challenge.

The findings of this study, while not conclusive, appears to show a differential effect based on gender and ethnicity, suggesting that further study is needed to understand the role of these factors in intervention outcome. It is of further significance to note, however, that in conducting this preliminary evaluation of the impact of the CLP on feelings of personal expressiveness in this population, an effort was made to evaluate the impact of the program in its "usual care" format (i.e., "out of the box" with no modifications). While this might be considered a limitation of this study because of the lack of a targeted intervention strategy, the differences observed between Hispanics and African-Americans raise interest for future study; whatever the reason behind these differences, it appears that individuals of differing ethnicities, at the very least, perceive interventions such as the CLP and that of Schwartz, Kurtines, and Montgomery (2005) differently and that these differences do impact their participation in such interventions.

In this context, this study's findings of a clear-cut effect showing an increase in feelings of personal expressiveness offers further support for the sparse literature that exists with respect to the "specificity of effects." Specifically, in contrast to the Schwartz 
et al. (2005) study, which implemented specific intervention activities meant to affect feelings of personal expressiveness, the fact that this study's non-specific intervention yields a relatively clear-cut (though moderated by exogenous variables) effect raises for future research the issue of whether this is a result of the CLP intervention implicitly including the same "active ingredient" (e.g., a focus on self-development by promoting personal strengths, whatever they may be, or skills development which promotes personal strengths) or whether it includes a different, perhaps even distinct ingredient, that has the same effect. Further study is needed, however, to make any specific claims about what this ingredient may be. On a broader level, however, this study provides some evidence that intervention amongst multi-ethnic adolescents from multi-ethnic contexts do show the same sorts of differential effects found in studies done using considerably less diverse samples from more ethnically homogenous contexts (Schwartz \& Montgomery, 2002; Ollech \& McCarthy, 1997; Schultheiss \& Blustein, 1994); this finding provides evidence that the call for study of ethnic and gender differences amongst intervention participants is both warranted and necessary if the process of intervention change is to be better understood.

\section{The Changing Lives Program Intervention Approach and}

\section{Feelings of Personal Expressiveness}

The second contribution this study makes is to further the on-going evaluation of the CLP intervention; specifically, this study suggests that increases in feelings of personal expressiveness are consistent with the overall theoretical orientation of the Changing Lives Program. Furthermore, this study's findings give preliminary evidence that the CLP intervention can continue to pursue more specific intervention strategies 
which target feelings of personal expressiveness, by maintaining a perspective which keeps the intervention participant at the center of the change process.

The CLP draws on a model of school counseling designed by Keys, Bemak, and Lockhart (1998) designed to target diverse mental health needs in troubled or at risk youth who attend alternative schools. The model emphasizes group counseling in order to serve more students in an intervention format which is directly relevant to students' needs. Within this format, the CLP groups address a variety of concerns based on participants' needs, dealing with issues such as anger management, troubled families, relationship problems, self-esteem, and alternative lifestyle concerns. The focus of each of these groups is on individual participants evaluating and making the changes they deem necessary to address the problems in their life. This "bottom-up" implementation strategy focuses on targeting developmental gains that assist youth in proactively guiding the systems/contexts that have an impact on their lives (Silverman \& Kurtines 1997; Kurtines \& Silverman, 1999). The CLP approach is consistent with many contemporary views of identity, in that adaptive identity development involves making decisions to take control of one's life, as well as the exploration of and commitment to one's potentials (Berzonsky, 1989; Côté, 1996; 1997; Dryer, 1994; Josselson, 1994; Waterman, 1995). Such an approach, placing the individual as the primary agent of change within their own life context, is also consistent with the findings of this study; that is, as the individual becomes more proactive in taking control of his or her own life, making decisions to foster his or her own potentials, he or she is acting in an increasingly personally expressive manner. 
The findings that feelings of personal expressiveness do, in fact, increase in an intervention context meant to empower individual self-change suggests that feelings of personal expressiveness has potential utility as a specific target for future intervention with this troubled adolescent populations. The specific effects of the intervention, however, suggest that not all intervention participants fare the same.

\section{Who is the CLP intervention affecting?}

The third main contribution of this study is its support of previous research which has found differential effects of gender and ethnicity on intervention outcome using samples of varying diversity (e.g. Schwartz \& Montgomery, 2002; Kortsch, 2003; LewisArango, 2003; Ollech \& McCarthy, 1997; Schultheiss \& Blustein, 1994). The CLP intervention appears to have a positive effect for female participants relative to control, but little positive effect for males. Most ethnic subgroups participating in the intervention show positive change, but a differential effect for African-Americans and Hispanics was found, in that African-Americans do not show improvement in their feelings of personal expressiveness scores, while Hispanics show a marked increase. The slight decline in African-Americans' feelings of personal expressiveness, however, appears almost identical to the decline in feelings of personal expressiveness shown by non-intervention African-Americans. This suggests that CLP has very little (if any) impact of on AfricanAmerican participants' feelings of personal expressiveness.

The overall increases of Hispanic individuals' feelings of personal expressiveness scores for both intervention and control conditions suggests that another factor outside of the CLP intervention may be involved in increasing these individuals' feelings of personal expressiveness scores. It is plausible that this effect may be explained by some 
aspect of the alternative high school environment particular in its effect on positive change in Hispanic individuals. As the dominant culture in Miami-Dade County, Hispanics may respond more favorably to specific interventions than African-American students who remain a much smaller subgroup in this area. By working within the Miami-Dade school system, specifically its alternative schools, the CLP intervention is actually nested within the intervention of the alternative school system. Hispanics may simply be responding more favorably to this school-implemented strategy. The answer, however, remains unclear.

The relatively large effect found for females and the considerably lesser effect for males strongly suggest a gender effect, perhaps based on social gender expectations which have also been shown to vary by ethnicity (Schwartz \& Montgomery, 2002; Betancourt \& Sheldon, 2001). Hispanic culture is characterized by strong gender-role values (e.g., "machismo" versus "marianismo") in the subgroups comprising the Hispanic cultural tradition (e.g., Cuban American, Mexican American, Puerto Rican; Schwartz, Kurtines, \& Montgomery, 2005; Baron, 1991). These cultural norms may have contributed to the perceived benefit of the experience of going along with the intervention. Coupled with the potentially differential response to the alternative high school intervention, it may be possible that the concurrent change in the Hispanic control group was due to these individuals already acting out the expected gendered norms for their culture-expressing themselves as "typically male" or "typically female." Without further study, however, it is not yet clear what factors might be involved in this trend particular to African-Americans and Hispanics within such a community-school setting, but the differential effect ethnicity seems to play in terms of its moderation of 
intervention outcome suggests there are real differences in how differing ethnicities respond to interventions such as the CLP. Furthermore, this differential effect suggests that future community-based interventions, in particular, because of the populations they serve, need to better account for effects that ethnic differences amongst its participants may have on intervention outcomes. Caution must be taken not to over-interpret this study's findings, however.

As suggested in recent work addressing research problems when working with minority children and young adults, differential effects for minority study participants are often taken to mean deficits for these participants without understanding the full meaning such results might offer if seen in a broader context (Fisher, Hoagwood, Boyce, Duster, Frank, Grisso, Levine, Macklin, Spencer, Takanishi, Trimble, \& Zayas, 2002). For instance, the decrease in feelings of personal expressiveness shown in African-American participants does not automatically imply that these individuals are faring worse than their Hispanic and Caucasian counterparts; it is feasible that cultural differences exist which further moderate, or potentially mediate self development in these various groups. Furthermore, cultural differences may exist which result in differing approaches toward identity development; previous studies, for instance, suggest that African-American adolescents often show significantly less identity exploration than other-ethnic peers (Spencer \& Markstrom-Adams, 1990). So while previous studies have suggested that feelings of personal expressiveness may be important in positive self development, these studies have been done using primarily homogeneous majority samples (Csikszentmihalyi, 1990b; 1988, 1975; Waterman et al., 2003; 1993) without addressing specific mechanisms of change which are now shown to be likely moderated by 
contextual exogenous variables such as gender and culture. Furthermore, by not automatically assuming that decreased identity exploration is a deficit in AfricanAmerican adolescents as cautioned by Fisher et al., (2002), future work may serve to better understand how such a "foreclosed" approach to identity development might have both potential benefits within the African-American community, but also associated difficulties for such individuals operating within a broader multi-cultural context (Schwartz \& Montgomery, 2002). Care needs to be exercised that the differential effects being seen here are not interpreted only from a one-sided monocultural perspective on positive development (Sue, 2004).

\section{Working in contexts of heterogeneity and diversity}

The questions which remain regarding the mechanisms of self-development of individuals such as those participating in the Changing Lives Program serve to underscore the continued need to pursue effectiveness research which pays particular attention to moderators of intervention response in real-world community settings. When coupled with related findings of previous CLP intervention studies (Kortsch, 2003; Lewis-Arango, 2003), the finding of this study, that feelings of personal expressiveness appears to be strongly associated with one's gender and ethnic socialization experiences, further suggests that continued outreach research sensitive toward understanding specificity of intervention effects for intervention subgroups is important to better understand the differential nature of "moderated moderation" effects, at least for gender and ethnicity, as theoretically meaningful potential exogenous variables with this population. 


\section{Limitations}

This study has several known limitations. At the time the data were collected, no records were kept regarding participant attrition, known to be especially high in alternative school settings. This raises the question of whether selection effects may play a part in the effect of the Changing Lives Program in that those who may fare worse in an intervention setting such as the CLP were excluded. Also, even though significant effects for the intervention condition were found, small sample size, especially with regard to smaller-represented subgroups may have resulted in being unable to detect smaller effect sizes that remain unidentified and understudied. Also, because the Control Condition spans only pre and post in the current study without a follow-up assessment, future studies might make better comparisons with the Intervention Condition with at least a third assessment point to understand if the changes seen in the comparison control might be considered developmentally normative within such an alternative high school setting. 


\section{REFERENCES}

Adelman, H. \& Taylor, L. (2003). On sustainability of project innovations as systemic change. Journal of Educational \& Psychological Consultation, 14(1), 1-25.

Betancourt, B. \& Sheldon, K. (2001). Social roles as mechanism for psychological need satisfaction within social groups. Journal of Personality and Social Psychology, 81(6), 1131-1143.

Betancourt, H. \& Lopez, S. (1993). The study of culture, ethnicity, and race in American psychology. American Psychologist, 48, 537-629.

Berzonsky, M. D. (1989). The self as a theorist: Individual differences in identity formation. International Journal of Personal Construct Psychology 2 2(4), 363376.

Brandtstaedter, J. \& Lerner, R. M. (Eds.). (1999). Action \& self-development: Theory and research through the life span. Thousand Oaks, CA: Sage.

Catalano, R. F., Berglund, M. L., J. A. M. Ryan, Lonczak, H., \& J. D. Hawkins (1999). Positive youth development in the United States: Research findings on evaluations of positive youth development programs. Washington, DC: U. S. Department of Health and Human Services.

Cole, J.B. (1998). Commonalities and differences. In Anderson, M.L. and Collins, P.H. (eds.). Race, Class, and Gender: An Anthology. Wadsworth, Belmont, CA, $175-$ 180.

Côté, J. E., \& Allahar, A. L. (1996). Generation on hold: Coming of age in the late twentieth century. New York: New York University Press.

Côté, J. E. (1997). An empirical test of the identity capital model. Journal of Adolescence, 20(5), 577-597.

Csikszentmihalyi, M. (1990a). Flow: The psychology of optimal experience. New York: Basic Books.

Csikszentmihalyi, M. (1990b) The domain of creativity. Theories of Creativity. Runco, M, ed. Sage Publications, 190-212.

Csikszentmihalyi, M. \& Larson, R. (1978) Intrinsic rewards in school crime. Crime \& Delinquency. 23(3), 322, 335.

Csikszentmihalyi, M. \& Rathunde, K. (1998). The development of the person: An experiential perspective on the ontogenesis of psychological complexity. In R. M. 
Lerner (Ed.), Handbook of child psychology, Vol 1: Theoretical models of human development. New York, NY: Wiley.

Damon, W. (2004). What is positive youth development? Annals of the American Academy of Political \& Social Science. Special Positive Development: Realizing the Potential of Youth, 591, 13-24.

Damon, W., \& Gregory, A. (2003). Bringing in a new era in the field of youth development. In R. M.. Lerner \& P. L. Benson (Eds.), Developmental assets and asset-building communities: Implications for research, policy, and practice. The search institute series on developmentally attentive community and society; developmental assets and asset-building communities: Implications for research, policy, and practice. (pp. 47-64). New York, NY, US: Kluwer Academic/Plenum Publishers.

Dryer, P. H. (1994). Designing curricular identity interventions for secondary schools. In S. L. Archer (Ed.), Interventions for adolescent identity development (pp. 121140).

Eccles, J. S. (1996). The power and difficulty of university-community collaboration. Journal of Research on Adolescence, 6, 81-86.

Elder, G. H. (1998a). The life course and human development. In R. M. Lerner (Ed.), Handbook of child psychology, Vol 1: Theoretical models of human development. New York, NY: Wiley.

Erickson, M. F., \& Weinberg, R. A. (1998). The children, youth, and family consortium: A University of Minnesota/ community partnership. In R. M. Lerner \& L. A. K. Simon (Eds.), University-community collaborations for the twenty-first century: Outreach scholarship for youth and families (pp. 185-201). New York: Garland.

Erickson, M. F., \& Weinberg, R. A. (1999). A broad and dynamic partnership: Minnesota's Children, Youth, and Family Consortium. In T. Chibucos \& R. M. Lerner (Eds.), Serving children and families through community-university partnerships: Success stories (pp. 231-236). Norwell, MA: Kluwer.

Erikson, E. H. (1959). Identity and the life cycle. New York: Norton.

Erikson, E. H. (1968). Identity: Youth and crisis. New York: Norton.

Ferrer-Wreder, L., Stattin, H., Lorente, C. C., Tubman, J., \& Adamson, L. (2003). Prevention and youth development programs: Across borders. New York: Kluwer Academic/Plenum.

Fisher, C. B. (1997). A relational perspective on ethics-in-science decision-making for research with vulnerable populations. IRB: A Review of Human Subjects Research, 19,1-4. 
Fisher, C., Hoagwood, K., Boyce, C., Duster, T., Frank, D., Grisso, T., Levine, R., Macklin, R., Spencer, M.B., Takanishi, R., Trimble, J.E., \& Zayas, L.H.. Research Ethics for Mental Health Science Involving Ethnic Minority Children and Youths. American Psychologist, 57, 12, 1024-1040.

Higgins-D'Alessandro, A., Fisher, C. B., \& Hamilton, M. G. (1998). Educating the applied developmental psychologist for university-community partnerships. In R. M. Lerner \& L. A. K. Simon (Eds.), University-community collaborations for the twenty-first century: Outreach scholarship for youth and families (pp. 157-183). New York: Garland.

Hinshaw, S. P. (2002). Intervention research, theoretical mechanisms, and causal processes related to externalizing behavior patterns. Development and Psychopathology, 14, 789-818.

Holmbeck, G. N. (1997). Toward terminological, conceptual, and statistical clarity in the study of mediators and moderators: Examples from child clinical and pediatric psychology literatures. Journal of Consulting and Clinical Psychology, 65, 599610.

Holmbeck, G. N., \& Shapera, W. (1999). Research methods with adolescents. In P. C. Kendall, J. N. Butcher, \& G. N. Holmbeck (Eds.), Handbook of research methods in clinical psychology (2nd ed., pp. 634-661). New York: Wiley.

Jensen, P., Hoagwood, K., \& Trickett, E. (1999). Ivory towers or earthen trenches? Community collaborations to foster "real world" research. Applied Developmental Science, 3(4), 206-212.

Josselson, R. (1994). The theory of identity development and the question of intervention: An introduction. In S. L. Archer, (Ed.), Interventions for adolescent identity development. Thousand Oaks, CA: Sage, 12-28.

Kazdin, A. E. (2001). Bridging the enormous gaps of theory with therapy research and practice. Journal of Clinical Child Psychology, 30(1), 59-66.

Keys, S., Bemak, F., Carpenter, S., \& King-Sears, M. (1998). Collaborative consultant: A new role for counselors serving at-risk youths. Journal of Counseling \& Development, 76(2), 123-133.

Keys, S. G., Bemak, F., \& Lockhart, E. J. (1998). Transforming school counseling to serve the mental health needs of at-risk youth. Journal of Counseling and Development, 76, 381-388.

Kortsch, G. (2003). The possible selves method in evaluating youth development intervention : the use of integrated qualitative/quantitative data analytic strategies (IQ-DAS). Unpublished Dissertation. Florida International University, Miami. 
Kortsch, G. (2001). Evaluating youth development interventions using the possible selves method: an investigation of the utility of the possible selves questionnaire qualitative extension (PSQ-QE). Unpublished Thesis. Florida International University, Miami.

Kurtines, W. M., Kortsch, G. A., \& Lewis Arango, L. (2001). Using qualitative markers to assess intervention impact on long-term positive change in identity trajectory. Paper presented at a symposium, Intervening to Promote Identity Development: How Do We Foster and Evaluate Positive Change, at the Eight Annual Conference of the Society for Research on Identity Formation, London, Ontario, Canada, May, 2001.

Kurtines, W. M., Montgomery, M. J., Kortsch, G., Lewis Arango, L. (in press). Does Intervention Change Anything? New Directions in Promoting Positive Youth Development. European Journal of Developmental Psychology

Lerner, R. M. (1995). America's youth in crisis: Challenges and options for programs and polices. Thousand Oaks, CA: Sage.

Lewis-Arango, L. (2003). The utility of an integrated qualitative/quantitative data analytic strategy (IQ-DAS) to evaluate interventions on positive qualitative change in the life course. Unpublished dissertation. Florida International University, Miami.

Lewis-Arango, L., \& Kurtines, W. (2005) LCI study: Outreach research and new directions in efficacy/effectiveness research. Manuscript in preparation. Florida International University, Miami.

Nakamura, J., \& Csikszentmihalyi, M. (2002). The concept of flow. In C. R. Snyder \& S. J. Lopez (Eds.), Handbook of positive psychology (pp. 89-105). Oxford: Oxford University Press.

Ollech, D. \& McCarthy, J. (1997). Impediments to identity formation in female adolescents. Psychoanalytic Psychology, 14, 65-80.

Parr, G., Montgomery, M., \& Bell, C. (1998). Flow theory as a model for enhancing student resilience. Professional School Counseling, 1(5), 26-31.

Peterson, N. \& Reid, A. (2003) Paths to psychosocial empowerment in an urban community: Sense of community and citizen participation in substance abuse prevention activities. Journal of Community Psychology, 31(1), 25-38.

Pittman, K. J. (2000). What youth need: Services, supports, and opportunities, the ingredients for youth. Paper presented at the White House Conference on Teenagers, Washington, DC, May 2, 2000. 
Schultheiss, D. \& Blustein, D. (1994) Contribution of family relationship factors to the identity formation process. Journal of Counseling Development, 73, 159-166.

Schwartz, S. \& Montgomery, M. (2002). Similarities or differences in identity development? The impact of acculturation on gender and identity process and outcome. The Journal of Youth and Adolescence. 31(5), 359-372.

Schwartz, S. J., Kurtines, W. K., \& Montgomery, M. J.,. A. (2005). A comparison of two approaches for facilitating identity exploration processes in emerging adults: an exploratory study. Journal of Adolescent Research.

Szcapocznik, J. \& Kurtines, W. (1993). Family psychology and cultural diversity: Opportunities for theory, research, and intervention. American Psychologist, 48, 400-407.

Silverman, W. K. \& Kurtines, W. M. (1997). Theory in child psychosocial treatment research: Have it or had it? A pragmatic alternative. Journal of Abnormal Child Psychology, 25(5), 359-366.

Silverman, W. K., Kurtines, W. M. (1999). A pragmatic perspective toward treating children with phobia and anxiety problems. In S. W. Russ, T. H. Ollendick, et al., (Eds.), Handbook of psychotherapies with children and families. Issues in clinical child psychology (pp. 505-521). New York: Kluwer Academic/Plenum Publishers.

Sorrell, G. \& Montgomery, J. (2001). Feminist perspectives on the relevance of Erikson's theory for contemporary identity development research. Identity, 1, 97-128.

Spencer, M.B. \& Markstrom-Adams, C.. (1990) Identity among racial and ethnic minority children in America. Child Development, 61, 290-310.

Spoth, R., Greenberg, M., Bierman, K., \& Redmond, C. (2004). PROSPER Communityuniversity partnership model for public education systems capacity-building for evidence-based, competence-building prevention. Prevention Science, 5(1), 31 39.

Sue, D. (2004) Whiteness and ethnocentric monoculturalism: Making the invisible visible. American Psychologist, 59(8), 761-769.

Swenson, S. (2003) An investigation of the relationship between transformative goals and troubled youth formative change goals and troubled youth psychosocial intervention response. Unpublished master's thesis. Florida International University, Miami.

Swenson, S. (2004). Participation in a positive youth development program and multiproblem alternative high school students' transformative goals: An investigation of the theoretical and methodological utility and validity of the transformative 
goal attainment scale (TGAS). Unpublished dissertation. Florida International University, Miami.

Waterman, A. S. (1990). Personal expressiveness: Philosophical and psychological foundations. Journal of Mind and Behavior, 11, 47-74.

Waterman, A. S. (1994). Ethical considerations in interventions for promoting identity development. In S. L. Archer, (Ed.), Interventions for adolescent identity development. (pp. 231-244). Thousand Oaks, CA: Sage.

Waterman, A. S. (1995). Eudaimonic theory: Self-realization and the collective good. In W. M. Kurtines \& J. L. Gewirtz (Eds.), Moral development: An introduction. (p. 255-278). Boston: Allyn \& Bacon.

Waterman, S. (1993). Finding something to do or someone to be: A eudaimonist perspective on identity formation. Discussions on Ego Identity. Kroger, L., ed. Lawrence Erlbaum Associates, Inc., 147-167.

Waterman, S., Schwartz, S., Goldbacher, E., Green, H., Miller, C., Philip, S. (2003). Predicting the subjective experience of intrinsic motivation: The roles of selfdetermination, the balance of challenges and skills, and self-realization values. Personality and Social Psychology Bulletin, 29, 10, 1-12. 